\title{
Using Hybrid Model to Evaluate Performance of Innovation and Technology Professionals in Marine Logistics Industry
}

\author{
Qunzhen Qu, ${ }^{1}$ Kuan-Yu Chen, ${ }^{2}$ Yu-Min Wei, ${ }^{3}$ Yanjun Liu, ${ }^{1}$ \\ Sang-Bing Tsai, ${ }^{4,5,6}$ and Weiwei Dong ${ }^{7}$ \\ ${ }^{1}$ School of Economics \& Management, Shanghai Maritime University, Shanghai 201306, China \\ ${ }^{2}$ Business School, Nankai University, Tianjin 300071, China \\ ${ }^{3}$ College of Tourism and Service Management, Nankai University, Tianjin 300071, China \\ ${ }^{4}$ Zhongshan Institute, University of Electronic Science and Technology of China, Guangdong 528402, China \\ ${ }^{5}$ Law School, Nankai University, Tianjin 300071, China \\ ${ }^{6}$ Business School, Tianjin University of Finance and Economics, Tianjin 300222, China \\ ${ }^{7}$ School of Economics and Management, Shanghai Institute of Technology, Shanghai 201418, China
}

Correspondence should be addressed to Sang-Bing Tsai; sangbing@hotmail.com and Weiwei Dong; weiweidong9494@163.com

Received 28 July 2015; Accepted 8 October 2015

Academic Editor: Paulina Golinska

Copyright (c) 2015 Qunzhen Qu et al. This is an open access article distributed under the Creative Commons Attribution License, which permits unrestricted use, distribution, and reproduction in any medium, provided the original work is properly cited.

With the development of marine logistics industry to grow, the government and corporate more and more attach importance to the performance evaluation of innovation and technology professionals. Combine the characteristics of marine logistics industry and innovative technology professionals to design a performance evaluation index of marine logistics industry in innovation and technology professionals, with the Analytic Hierarchy Process (AHP) to determine the weights of the various performance indicatorsf and through the establishment of fuzzy comprehensive evaluation model to make the problems of complex performance evaluation quantification and then come to their performance evaluation results, and provide reference methods and recommendations for innovation and technology professionals in performance evaluation theory and practice of marine logistics industry.

\section{Introduction}

Marine logistics industry is an important part of marine industries, which refers to using of the sea water, ocean space, or sea products as the production process of logistics industry, including ocean transportation, port handling, warehousing, port value-added services, and wholesale and retail trade industry. It plays a very important role in the development of marine economy [1-3]. Under the vigorous opportunity of construction of international shipping center and innovation and technology professionals as the high-end talent, its performance evaluation system for the whole development situation has practical application value. Innovation and technology professionals refer to those who have high scientific quality, breaking through the existing theory, viewpoint, method, and technique in order to obtain the creative achievements and through the creative scientific research achievements to promote scientific and technological progress and contribute to social development and human progress $[4,5]$. President Hu Jintao discussed the importance of innovation and technology professionals' development in China in the Chinese Academy of Sciences and Chinese Academy of Engineering Academician Conference, held firmly and consistently to train innovation and technology professionals, which is the inevitable requirement of improving the independent innovation ability and the building of an innovative country. We must adhere to the talent resource as the first resource of strategic thinking, stepping up construction of innovation and technology professionals team [5]. 


\section{Performance Evaluation of Marine Logistics Industry in Innovation and Technology Professionals}

2.1. Design of Performance Evaluation System. The performance evaluation of innovation and technology professionals is a comprehensive, complex problem affected by multiple indicators. The establishment of evaluation index should follow the "organizational goals consistency," "the reliability and validity," "integrity and controllability," and the principle of "combining the scientific nature and operability" $[2,3]$. There is plenty of literature review and a lot of experience for performance evaluation, combined with the existence of the innovative talents of science and technology and the characteristics of marine logistics industry, based on key performance indicators (KPI) and objective management, from the three aspects of job performance, work ability, and work attitude, to design the innovative talents of science and technology's performance evaluation index of marine logistics industry.

\subsection{The Construction of Performance Evaluation Index}

2.2.1. Job Performance. The performance index is generated by the working behavior results, which directly reflects the ultimate goal of performance management. These indicators can be the key job responsibilities for the position or a stage of the project and also be a year's comprehensive performance $[6,7]$, according to the characteristics of the marine logistics industry and the innovative talents of science and technology, which can be designed from the two aspects of funding and technical profit and customer satisfaction. From the perspective of funding and technical profit, it mainly reflects that the scientific and technological personnel through innovative research developed product or project to gain national recognition and use, at the same time, advances in technology which can bring benefits to the enterprise and cost savings, mainly selecting the research funding of national gift or related equipment, new technology to reduce the cost of the contribution rate, project implementation conversion rate, scientific and technological achievements conversion rate, and the budget rate of research funding as five tertiary indicators. From the perspective of customer satisfaction, it mainly reflects whether the customer is satisfied with the product and project of research or not and whether there is an effect on promoting the status of enterprise in the industry or not, mainly selecting the customer market share and customer complaint rate as two tertiary indicators.

2.2.2. Work Ability. Work ability index which reflects a person in a position of a set of standardized requirements (different position needs different abilities) according to the characteristics of the innovative talents of science and technology can be designed from social influence competence (social), core competence (enterprise), and the ability of studying development (itself). From the social perspective, it mainly reflects its research results' influence on the whole social, mainly selecting the number of papers by SCI, EI, and ISTP retrieval, the number of published works, reputation in the industry, success rate of project application, and teaching students' satisfaction as five tertiary indicators. From the perspective of enterprise, it reflects that the core competence of talents of science and technology has to bring benefits to the enterprise, mainly selecting the scientific research ability, keen insight and flexibility, logical thinking ability, innovation ability, and business expansion ability as five tertiary indicators. From the perspective of itself, it reflects the talents of science and technology through their own efforts to learn about the development situation of domestic and foreign industry and bring more people to understand and enter the marine logistics industry, in order to provide the excellent talents for the long-term development of enterprises, mainly selecting the number of people entering the international academic conference, number of people studying abroad, number of training and mining ocean logistics staff, number of marine logistics lectures and participants, and the building of marine logistics team as five tertiary indicators.

2.2.3. Work Attitude. Work attitude reflects the tendencies of personnel for the behavioral evaluation, according to the characteristics of the innovative talents of science and technology, which can be designed from the two aspects of job satisfaction and the team cooperation. Job satisfaction reflects, in the process of working in the organization, benign feelings of mental state for the work itself and its related aspects, mainly selecting the confidentiality, sense of responsibility, enthusiasm for work, and discipline for projects of the new marine logistics industry as four tertiary indicators. Team cooperation reflects if team members have the consciousness of cooperation and communicate with each other, thus improving overall research and development ability. The sharing of knowledge and cooperation spirit are mainly selected as two tertiary indicators. In an ordered form, the index for performance evaluation of marine logistics industry in innovation and technology professionals is shown in Table 1.

\section{The Construction of Model for Performance Evaluation of Marine Logistics Industry in Innovation and Technology Professionals}

In the study of performance evaluation system, many scholars use different evaluation methods, such as the Analytic Hierarchy Process, Grey Correlation Evaluation Method, Fuzzy Comprehensive Evaluation Method, Method of Data Envelopment, The Neural Network, and Factor Analysis Method. This research adopts the Analytic Hierarchy Process and Fuzzy Comprehensive Evaluation Method. In the early 1970s, the United States well-known operations research Professor Satty (T. L. Satty) at the University of Pittsburgh was the first to put forward the Analytic Hierarchy Process, making research on the theory and practical application of the Analytic Hierarchy Process in 1994 [8-11].

For the determination of index weight, most studies used subjective judgment; it makes the degree of the indexes for evaluation lack logic and consistency. The Analytic Hierarchy 
TABLE 1: Index for performance evaluation of marine logistics industry in innovation and technology professionals.

\begin{tabular}{|c|c|c|c|}
\hline Goal indicators & Level indicators & Secondary indicators & Tertiary indicators \\
\hline \multirow{19}{*}{$\begin{array}{l}\text { Performance of } \\
\text { marine logistics } \\
\text { industry in } \\
\text { innovation and } \\
\text { technology } \\
\text { professionals } V\end{array}$} & \multirow[t]{2}{*}{ Job performance $V_{1}$} & Funding and technical profit $V_{11}$ & $\begin{array}{l}\text { Research funding of national gift or related equipment } V_{111} \\
\text { New technology to reduce the cost of the contribution rate } \\
V_{112} \\
\text { Project implementation conversion rate } V_{113} \\
\text { Scientific and technological achievements conversion rate } \\
V_{114} \\
\text { Budget rate of research funding } V_{115}\end{array}$ \\
\hline & & Customer satisfaction $V_{12}$ & $\begin{array}{l}\text { Customer market share } V_{121} \\
\text { Customer complaint rate } V_{122} \\
\text { Number of papers by SCI, EI, and ISTP retrieval } V_{211} \\
\text { Number of published works } V_{212}\end{array}$ \\
\hline & \multirow{13}{*}{ Work ability $V_{2}$} & \multirow[t]{3}{*}{ Social influence competence $V_{21}$} & Reputation in the industry $V_{213}$ \\
\hline & & & Success rate of project application $V_{214}$ \\
\hline & & & Teaching students' satisfaction $V_{215}$ \\
\hline & & \multirow{5}{*}{ Core competence $V_{22}$} & Scientific research ability $V_{221}$ \\
\hline & & & $\begin{array}{l}\text { Keen insight and flexibility } V_{222} \\
\text { Logical thinking ability } V\end{array}$ \\
\hline & & & $\begin{array}{l}\text { Logical thinking ability } V_{223} \\
\text { Innovation ability } V_{224}\end{array}$ \\
\hline & & & Business expansion ability $V_{225}$ \\
\hline & & & $\begin{array}{l}\text { Number of people entering the international academic } \\
\text { conference } V_{231}\end{array}$ \\
\hline & & \multirow{5}{*}{ Ability of studying development $V_{23}$} & Number of people studying abroad $V_{232}$ \\
\hline & & & Number of training and mining ocean logistics staff $V_{233}$ \\
\hline & & & Number of marine logistics lectures and participants $V_{234}$ \\
\hline & & & Building of marine logistics team $V_{235}$ \\
\hline & & & Confidentiality $V_{311}$ \\
\hline & \multirow{4}{*}{ Work attitude $V_{3}$} & \multirow{3}{*}{ Job satisfaction $V_{31}$} & Sense of responsibility $V_{312}$ \\
\hline & & & Enthusiasm for work $V_{313}$ \\
\hline & & & Discipline $V_{314}$ \\
\hline & & Team cooperation $V_{32}$ & $\begin{array}{l}\text { Sharing of knowledge } V_{321} \\
\text { Cooperation spirit } V_{322}\end{array}$ \\
\hline
\end{tabular}

Process (AHP) is a systematic method for multicriteria decision-making (MCDM). This method can be used to logically solve complex, unstructured economic, social, and managerial decision-making problems. To a great extent, this approach ensures that the results appraise evaluation logic and rationality and reduce the interference of subjective factors and then make the weights of index system of incline reasonable, in order to improve the accuracy of the appraisal [12-14]. At the meantime, because specialists have different opinion on performance evaluation of marine logistics industry in innovation and technology professionals, it is difficult to directly use statistical methods to determine the specific judgment value of these factors; therefore, based on the above reasons, this research adopts the Analytic Hierarchy Process and Fuzzy Comprehensive Evaluation Method.

3.1. Build Mathematical Model. The mathematical model is as follows:

(1) Establish quantitative scale of importance and determine the relative importance of various factors and quantitative index.
(2) It is the hierarchical evaluation index.

(3) It is made by the experts of the relative importance between various factors and then in accordance with Satty's 1 9 scales $[8,15,16]$ to assign the value and statistics experts' opinions and compare the results of the relative importance of the various factors and fill in the judgment matrix.

(4) Calculate the weight of each factor.

(5) Check consistency.

(6) Build the evaluation set. $U=\left\{U_{1}, U_{2}, \ldots, U_{m}\right\}$, and, among them, $U_{1}, U_{2}, \ldots, U_{m}$, means $m$ kinds of comments; for example, $U=$ \{excellent, good, medium, passing, fail\}.

(7) Build factor set, divided into a subset of the factors set $V$, as a set of second-level factors $V=\left\{V_{1}, V_{2}, \ldots, V_{n}\right\}$ and as $V_{i}=\left\{V_{i 1}, V_{i 2}, \ldots, V_{i k i}\right\}, i=1,2, \ldots, n$.

(8) Determine the weight of evaluation index. $W=\left\{W_{1}\right.$, $\left.W_{2}, \ldots, W_{m}\right\}, \sum_{k=1}^{m} W=1$, and $0<W_{k}<1$. Among them, $W$ represents $m$ factors index made by $\left(W_{1}\right.$, $\left.W_{2}, \ldots, W_{m}\right)$. 
(9) Build evaluation matrix. Assume the $i$ 's single factor evaluation vector is $R_{i}=\left(r_{i 1}, r_{i 2}, \ldots, r_{i m}\right)$; it can be seen as a fuzzy subset of $U$, and it means the degree of membership of the $i$ factor evaluation for the $k$ level; $n$ factors evaluation matrix is

$$
\left[\begin{array}{c}
R_{1} \\
R_{2} \\
\vdots \\
R_{4}
\end{array}\right]=\left[\begin{array}{cccc}
r_{11} & r_{12} & \cdots & r_{1 m} \\
r_{21} & r_{22} & \cdots & r_{2 m} \\
\vdots & \vdots & & \vdots \\
r_{n 1} & r_{n 2} & \cdots & r_{n m}
\end{array}\right] .
$$

(10) Comprehensive evaluation: in determining the membership matrix $R$ and evaluation of vector $W$, we can use the comprehensive evaluation of fuzzy transformation: $B=W \circ R$, where "o" on behalf of the operation is "choosing big or small" operator. In the four common models $-M=(\wedge, \vee)$-make $B=\left(b_{1}, b_{2}, \ldots, b_{m}\right)=A \circ R, b_{j}=\vee\left(a_{i} \wedge r_{i j}\right)=$ $\max \left\{\min \left(a_{1}, r_{1 j}\right), \min \left(a_{2}, r_{2 j}\right), \ldots, \min \left(a_{n}, r_{n j}\right)\right\}$.

3.2. Case Study. The Shanghai performance of marine logistics industry in innovation and technology professionals, according to the above index of performance evaluation system, gives a sample to illustrate the application of the Analytic Hierarchy Process and Fuzzy Comprehensive Evaluation Method [17-19]:

(1) Establish the importance of the quantitative scale: "1" represents equally important, that is, the same importance as the two indicators; " 3 " represents more important, that is, an indicator of a little more importance than another; " 5 " represents obviously important, an indicator with another indicator which has obvious importance; " 7 " represents very important, that is, very important compared to an indicator with another indicator; "9" represents absolute importance, that is, an indicator of the importance of completely overwhelming another indicator. In the study, the Analytic Hierarchy Process is with a ratio of 1 to 9 scales, because this ratio is more in line with people's mental habits during judgment [20-22].

(2) Statistics expert's scoring on the importance of the evaluation elements builds a judgment matrix, as the funding and technical profit $V_{11}$, Table 2 .

(3) Calculating the weight, element normalization, and each row is as shown in Table 3.

(4) Check the consistency of the matrix.

For the consistency of the matrix, we can make simple estimates, making weighted vector right by judgment matrix, and then get a new vector. And then, in turn, we use this new vector of each weight divided by the corresponding weight vector component and then get a new vector, divided by the number of components; getting the value is the maximum characteristic approximation $\left(\lambda_{\max }\right)$; this value is much closer to the consistency of judgment matrix which is better [23-27]. Using this method to get $\lambda_{\max }$ of $V_{11}$ factors approximation is 5.38 , and the matrix of order number 5 suggests that the consistency of expert scoring is higher; the result is reasonable and effective.
TABLE 2: The judge matrix of $V_{11}$ ' subfactors.

\begin{tabular}{lccccc}
\hline Factor $V_{11}$ & $V_{111}$ & $V_{112}$ & $V_{113}$ & $V_{114}$ & $V_{115}$ \\
\hline$V_{111}$ & 1 & $1 / 3$ & $1 / 5$ & $1 / 7$ & $1 / 3$ \\
$V_{112}$ & 3 & 1 & $1 / 5$ & $1 / 5$ & 3 \\
$V_{113}$ & 5 & 5 & 1 & $1 / 3$ & 3 \\
$V_{114}$ & 7 & 5 & 3 & 1 & 7 \\
$V_{115}$ & 3 & $1 / 3$ & $1 / 3$ & $1 / 7$ & 1 \\
\hline
\end{tabular}

TABLE 3: Evaluation results of $V_{11}$ ' subfactors.

\begin{tabular}{lccccccc}
\hline Project & \multicolumn{4}{c}{ Normalized results } & & Sum of rows & Weight \\
\hline$V_{111}$ & 0.05 & 0.03 & 0.04 & 0.08 & 0.02 & 0.22 & 0.044 \\
$V_{112}$ & 0.16 & 0.08 & 0.04 & 0.11 & 0.21 & 0.6 & 0.12 \\
$V_{113}$ & 0.26 & 0.43 & 0.21 & 0.18 & 0.21 & 1.29 & 0.258 \\
$V_{114}$ & 0.37 & 0.43 & 0.64 & 0.55 & 0.49 & 2.48 & 0.496 \\
$V_{115}$ & 0.16 & 0.03 & 0.07 & 0.08 & 0.07 & 0.41 & 0.082 \\
\hline
\end{tabular}

(5) The same as above, get the weight of each factor, such as in Table 4 . At the same time, by calculating the $\lambda_{\max }$ values close to the order number, show that the results are reasonable and effective.

(6) Build the evaluation set. The results of the evaluation of each indicator for performance evaluation of marine logistics industry in innovation and technology professionals are divided into 5 levels-excellent, good, medium, general, and poor-and then this performance evaluation of marine logistics industry in innovation and technology professionals' remark set is $U=$ \{excellent, good, medium, general, poor .

(7) Determine evaluation indicators and their weights. That performance evaluation of marine logistics industry in innovation and technology professionals includes two level indicators: the experts statistical results such as in Table 5 and weight in the above application of Analytic Hierarchy Process which has been worked out.

(8) Build three level indicators' evaluation matrix. From Table 5, for research funding of national gift or related equipment $V_{111}$, one expert thinks it is excellent, three consider it is good, three describe it as medium, two consider it general, and one thinks it be poor, so its evaluation index vector $R_{111}=\left(\begin{array}{lllll}0.1 & 0.3 & 0.3 & 0.2 & 0.1\end{array}\right)$; in the same way, funding and technical profit $V_{11}$ for other three indexes of evaluation vector in turn is

$$
\begin{aligned}
& R_{112}=\left(\begin{array}{lllll}
0.2 & 0.3 & 0.3 & 0.1 & 0.1
\end{array}\right), \\
& R_{113}=\left(\begin{array}{lllll}
0.1 & 0.3 & 0.4 & 0.2 & 0
\end{array}\right), \\
& R_{114}=\left(\begin{array}{lllll}
0.2 & 0.2 & 0.3 & 0.2 & 0.1
\end{array}\right), \\
& R_{115}=\left(\begin{array}{lllll}
0.1 & 0.4 & 0.2 & 0.2 & 0.1
\end{array}\right),
\end{aligned}
$$

and then

$$
R_{11}=\left[\begin{array}{ccccc}
0.1 & 0.3 & 0.3 & 0.2 & 0.1 \\
0.2 & 0.3 & 0.3 & 0.1 & 0.1 \\
0.1 & 0.3 & 0.4 & 0.2 & 0 \\
0.2 & 0.2 & 0.3 & 0.2 & 0.1 \\
0.1 & 0.4 & 0.2 & 0.2 & 0.1
\end{array}\right]
$$


TABLE 4: The weight of each factor and its subfactors.

\begin{tabular}{lc}
\hline Project & Weight \\
\hline$V_{1}$ & 0.63 \\
$V_{2}$ & 0.26 \\
$V_{3}$ & 0.11 \\
$V_{11}$ & 0.75 \\
$V_{12}$ & 0.25 \\
$V_{121}$ & 0.83 \\
$V_{122}$ & 0.17 \\
$V_{211}$ & 0.114 \\
$V_{212}$ & 0.076 \\
$V_{213}$ & 0.226 \\
$V_{221}$ & 0.31 \\
$V_{222}$ & 0.15 \\
$V_{223}$ & 0.15 \\
$V_{224}$ & 0.47 \\
$V_{225}$ & 0.04 \\
$V_{231}$ & 0.066 \\
$V_{232}$ & 0.132 \\
$V_{233}$ & 0.504 \\
$V_{234}$ & 0.034 \\
$V_{235}$ & 0.264 \\
$V_{311}$ & 0.29 \\
$V_{312}$ & 0.49 \\
$V_{313}$ & 0.15 \\
$V_{314}$ & 0.07 \\
$V_{21}$ & 0.2 \\
$V_{214}$ & 0.532 \\
$V_{215}$ & 0.052 \\
$V_{321}$ & 0.25 \\
$V_{322}$ & 0.75 \\
$V_{31}$ & 0.75 \\
$V_{32}$ & 0.25 \\
$V_{22}$ & 0.6 \\
$V_{23}$ & 0.2 \\
\hline &
\end{tabular}

and, in the same way,

$$
\begin{aligned}
& R_{12}=\left[\begin{array}{lllll}
0.2 & 0.3 & 0.2 & 0.1 & 0.1 \\
0.3 & 0.2 & 0.3 & 0.1 & 0.1
\end{array}\right], \\
& R_{21}=\left[\begin{array}{llllc}
0.3 & 0.4 & 0.2 & 0.1 & 0 \\
0.2 & 0.3 & 0.3 & 0.2 & 0 \\
0.1 & 0.2 & 0.3 & 0.2 & 0.2 \\
0.2 & 0.4 & 0.1 & 0.2 & 0.1 \\
0.3 & 0.2 & 0.2 & 0.2 & 0.1
\end{array}\right], \\
& R_{22}=\left[\begin{array}{lllll}
0.2 & 0.3 & 0.3 & 0.1 & 0.1 \\
0.2 & 0.2 & 0.3 & 0.2 & 0.1 \\
0.2 & 0.1 & 0.4 & 0.2 & 0.1 \\
0.3 & 0.3 & 0.2 & 0.1 & 0.1 \\
0.2 & 0.2 & 0.2 & 0.2 & 0.2
\end{array}\right],
\end{aligned}
$$

$$
\begin{aligned}
& R_{23}=\left[\begin{array}{llllc}
0.3 & 0.3 & 0.2 & 0.1 & 0.1 \\
0.2 & 0.4 & 0.2 & 0.2 & 0 \\
0.2 & 0.3 & 0.4 & 0.1 & 0 \\
0.3 & 0.3 & 0.3 & 0.1 & 0 \\
0.2 & 0.4 & 0.2 & 0.1 & 0.1
\end{array}\right], \\
& R_{31}=\left[\begin{array}{llllc}
0.2 & 0.3 & 0.2 & 0.3 & 0 \\
0.4 & 0.3 & 0.1 & 0.1 & 0.1 \\
0.3 & 0.2 & 0.1 & 0.2 & 0.2 \\
0.3 & 0.3 & 0.1 & 0.2 & 0.1
\end{array}\right], \\
& R_{32}=\left[\begin{array}{llllc}
0.4 & 0.2 & 0.2 & 0.1 & 0.1 \\
0.2 & 0.4 & 0.3 & 0.1 & 0
\end{array}\right] .
\end{aligned}
$$

(9) Build the secondary evaluation matrix. Table 5 shows the three levels of indicators weight vector, respectively:

$$
\begin{aligned}
& W_{11}=\left(\begin{array}{lllll}
0.044 & 0.12 & 0.258 & 0.496 & 0.082
\end{array}\right), \\
& W_{12}=\left(\begin{array}{ll}
0.83 & 0.17
\end{array}\right) \text {, } \\
& W_{21}=\left(\begin{array}{lllll}
0.114 & 0.076 & 0.226 & 0.532 & 0.052
\end{array}\right) \text {, } \\
& W_{22}=\left(\begin{array}{lllll}
0.311 & 0.152 & 0.152 & 0.469 & 0.038
\end{array}\right), \\
& W_{23}=\left(\begin{array}{lllll}
0.066 & 0.132 & 0.504 & 0.034 & 0.264
\end{array}\right), \\
& W_{31}=\left(\begin{array}{llll}
0.29 & 0.49 & 0.15 & 0.07
\end{array}\right), \\
& W_{32}=\left(\begin{array}{ll}
0.25 & 0.75
\end{array}\right) \text {. }
\end{aligned}
$$

Based on $B=W \circ R$, the following can be concluded:

$$
\begin{aligned}
B_{11} & =W_{11} \circ R_{11} \\
& =\left(\begin{array}{lllll}
0.044 & 0.12 & 0.258 & 0.496 & 0.082
\end{array}\right)
\end{aligned}
$$$$
\circ\left[\begin{array}{ccccc}
0.1 & 0.3 & 0.3 & 0.2 & 0.1 \\
0.2 & 0.3 & 0.3 & 0.1 & 0.1 \\
0.1 & 0.3 & 0.4 & 0.2 & 0 \\
0.2 & 0.2 & 0.3 & 0.2 & 0.1 \\
0.1 & 0.4 & 0.2 & 0.2 & 0.1
\end{array}\right]
$$

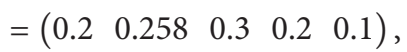

$B_{12}=\left(\begin{array}{lllll}0.2 & 0.3 & 0.2 & 0.1 & 0.1\end{array}\right)$,

$B_{21}=\left(\begin{array}{lllll}0.2 & 0.4 & 0.226 & 0.2 & 0.2\end{array}\right)$,

$B_{22}=\left(\begin{array}{lllll}0.3 & 0.3 & 0.3 & 0.152 & 0.1\end{array}\right)$,

$B_{23}=\left(\begin{array}{lllll}0.2 & 0.3 & 0.4 & 0.1 & 0.1\end{array}\right)$,

$B_{31}=\left(\begin{array}{lllll}0.4 & 0.3 & 0.2 & 0.29 & 0.15\end{array}\right)$,

$B_{32}=\left(\begin{array}{lllll}0.25 & 0.4 & 0.3 & 0.1 & 0.1\end{array}\right)$, 
TABLE 5: Evaluation index weight and expert scoring results.

\begin{tabular}{|c|c|c|c|c|c|c|c|}
\hline \multicolumn{3}{|c|}{ Indicators and weights } & Excellent & Good & Medium & General & Poor \\
\hline \multirow{7}{*}{$\begin{array}{l}\text { Job performance } \\
V_{1} \\
(0.63)\end{array}$} & \multirow{5}{*}{$\begin{array}{l}\text { Funding and technical } \\
\text { profit } V_{11} \\
(0.75)\end{array}$} & $\begin{array}{l}\text { Research funding of national gift or } \\
\text { related equipment } V_{111}(0.044)\end{array}$ & 1 & 3 & 3 & 2 & 1 \\
\hline & & $\begin{array}{l}\text { New technology to reduce the cost } \\
\text { of the contribution rate } V_{112}(0.12)\end{array}$ & 2 & 3 & 3 & 1 & 1 \\
\hline & & $\begin{array}{l}\text { Project implementation conversion } \\
\text { rate } V_{113}(0.258)\end{array}$ & 1 & 3 & 4 & 2 & 0 \\
\hline & & $\begin{array}{l}\text { Scientific and technological } \\
\text { achievements conversion rate } V_{114} \\
(0.496)\end{array}$ & 2 & 2 & 3 & 2 & 1 \\
\hline & & $\begin{array}{l}\text { Budget rate of research funding } V_{115} \\
(0.082)\end{array}$ & 1 & 4 & 2 & 2 & 1 \\
\hline & \multirow{2}{*}{$\begin{array}{l}\text { Customer satisfaction } V_{12} \\
(0.25)\end{array}$} & Customer market share $V_{121}(0.83)$ & 2 & 3 & 2 & 1 & 1 \\
\hline & & Customer complaint rate $V_{122}(0.17)$ & 3 & 2 & 3 & 1 & 1 \\
\hline \multirow{15}{*}{$\begin{array}{l}\text { Work ability } V_{2} \\
(0.26)\end{array}$} & \multirow{5}{*}{$\begin{array}{l}\text { Social influence } \\
\text { competence } V_{21} \\
(0.2)\end{array}$} & $\begin{array}{l}\text { Number of papers by SCI, EI, and } \\
\text { ISTP retrieval } V_{211}(0.114)\end{array}$ & 3 & 4 & 2 & 1 & 0 \\
\hline & & $\begin{array}{l}\text { Number of published works } V_{212} \\
(0.076)\end{array}$ & 2 & 3 & 3 & 2 & 0 \\
\hline & & $\begin{array}{l}\text { Reputation in the industry } V_{213} \\
(0.226)\end{array}$ & 1 & 2 & 3 & 2 & 2 \\
\hline & & $\begin{array}{l}\text { Success rate of project application } \\
V_{214}(0.532)\end{array}$ & 2 & 4 & 1 & 2 & 1 \\
\hline & & $\begin{array}{l}\text { Teaching students' satisfaction } V_{215} \\
(0.052)\end{array}$ & 3 & 2 & 2 & 2 & 1 \\
\hline & \multirow{5}{*}{$\begin{array}{l}\text { Core competence } V_{22} \\
(0.6)\end{array}$} & Scientific research ability $V_{221}(0.311)$ & 2 & 3 & 3 & 1 & 1 \\
\hline & & $\begin{array}{l}\text { Keen insight and flexibility } V_{222} \\
(0.152)\end{array}$ & 2 & 2 & 3 & 2 & 1 \\
\hline & & Logical thinking ability $V_{223}(0.152)$ & 2 & 1 & 4 & 2 & 1 \\
\hline & & Innovation ability $V_{224}(0.469)$ & 3 & 3 & 2 & 1 & 1 \\
\hline & & $\begin{array}{l}\text { Business expansion ability } V_{225} \\
(0.038)\end{array}$ & 2 & 2 & 2 & 2 & 2 \\
\hline & \multirow{5}{*}{$\begin{array}{l}\text { Ability of studying } \\
\text { development } V_{23} \\
(0.2)\end{array}$} & $\begin{array}{l}\text { Number of people entering the } \\
\text { international academic conference } \\
V_{231}(0.066)\end{array}$ & 3 & 3 & 2 & 1 & 1 \\
\hline & & $\begin{array}{l}\text { Number of people studying abroad } \\
V_{232}(0.132)\end{array}$ & 2 & 4 & 2 & 2 & 0 \\
\hline & & $\begin{array}{l}\text { Number of training and mining } \\
\text { ocean logistics staff } V_{233}(0.504)\end{array}$ & 2 & 3 & 4 & 1 & 0 \\
\hline & & $\begin{array}{l}\text { Number of marine logistics lectures } \\
\text { and participants } V_{234}(0.034)\end{array}$ & 3 & 3 & 3 & 1 & 0 \\
\hline & & $\begin{array}{l}\text { Building of marine logistics team } \\
V_{235}(0.264)\end{array}$ & 2 & 4 & 2 & 1 & 1 \\
\hline \multirow{6}{*}{$\begin{array}{l}\text { Work attitude } V_{3} \\
(0.11)\end{array}$} & \multirow{4}{*}{$\begin{array}{l}\text { Job satisfaction } V_{31} \\
(0.75)\end{array}$} & Confidentiality $V_{311}(0.29)$ & 2 & 3 & 2 & 3 & 0 \\
\hline & & Sense of responsibility $V_{312}(0.49)$ & 4 & 3 & 1 & 1 & 1 \\
\hline & & Enthusiasm for work $V_{313}(0.15)$ & 3 & 2 & 1 & 2 & 2 \\
\hline & & Discipline $V_{314}(0.07)$ & 3 & 3 & 1 & 2 & 1 \\
\hline & \multirow{2}{*}{$\begin{array}{l}\text { Team cooperation } V_{32} \\
(0.25)\end{array}$} & Sharing of knowledge $V_{321}(0.25)$ & 4 & 2 & 2 & 1 & 1 \\
\hline & & Cooperation spirit $V_{322}(0.75)$ & 2 & 4 & 3 & 1 & 0 \\
\hline
\end{tabular}


and then

$$
\begin{aligned}
& R_{1}=\left(\begin{array}{ccccc}
0.2 & 0.258 & 0.3 & 0.2 & 0.1 \\
0.2 & 0.3 & 0.2 & 0.1 & 0.1
\end{array}\right), \\
& R_{2}=\left(\begin{array}{ccccc}
0.2 & 0.4 & 0.226 & 0.2 & 0.2 \\
0.3 & 0.3 & 0.3 & 0.152 & 0.1 \\
0.2 & 0.3 & 0.4 & 0.1 & 0.1
\end{array}\right), \\
& R_{3}=\left(\begin{array}{lllll}
0.4 & 0.3 & 0.2 & 0.29 & 0.15 \\
0.25 & 0.4 & 0.3 & 0.1 & 0.1
\end{array}\right) .
\end{aligned}
$$

(10) Construction level evaluation matrix is

$$
\begin{aligned}
& W_{1}=\left(\begin{array}{ll}
0.75 & 0.25
\end{array}\right), \\
& W_{2}=\left(\begin{array}{lll}
0.2 & 0.6 & 0.2
\end{array}\right), \\
& W_{3}=\left(\begin{array}{ll}
0.75 & 0.25
\end{array}\right),
\end{aligned}
$$

and then

$$
R=\left(\begin{array}{ccccc}
0.2 & 0.258 & 0.3 & 0.2 & 0.1 \\
0.3 & 0.3 & 0.3 & 0.2 & 0.2 \\
0.4 & 0.3 & 0.25 & 0.29 & 0.15
\end{array}\right)
$$

(11) Calculate the final results of the evaluation. $W=$ $\left(\begin{array}{lll}0.63 & 0.26 & 0.11\end{array}\right) ; B=W \circ R=\left(\begin{array}{lllll}0.26 & 0.26 & 0.3 & 0.2 & 0.2\end{array}\right)$; by normalization, $B=\left(\begin{array}{lllll}0.21 & 0.21 & 0.24 & 0.17 & 0.17\end{array}\right)$.

According to the principle of maximum degree of membership, that performance evaluation level of marine logistics industry in innovation and technology professionals is "medium." From the view of the probability theory, about $21 \%$ of the experts believe that the performance is very good, $24 \%$ of the experts believe that it is medium, $17 \%$ of the experts believe that it is general, and $17 \%$ of the experts believe that it is poor.

\section{Conclusions and Recommendations}

With the development of marine logistics industry to grow, the government and corporate more and more attach importance to the performance evaluation of innovation and technology professionals. The study combines the characteristics of marine logistics industry and innovative technology professionals to design a performance evaluation index of marine logistics industry in innovation and technology professionals. We use the mathematical model of performance evaluation of complex talent problem in order to carry on the effective performance appraisal and provide opinions for the government and enterprises in the marine logistics talents' introduction, training, and incentives.

From the results of performance evaluation of marine logistics industry in innovation and technology professionals, its performance does not reach the excellent level. The government and enterprise should provide proper incentives for innovative talents of science and technology and then improve the level of its performance. It has a very important effect for marine logistics industry development.
The results demonstrated that the method proposed in this study provides theoretical contributions and can be applied to business.

\section{Conflict of Interests}

The authors declare that there is no conflict of interests regarding the publication of this paper.

\section{References}

[1] H. Wang and W.-J. Su, "The marine logistics industry present situation and development countermeasures of Fujian Province," Journal of Jimei University (Natural Science Edition), vol. 4, p. 124, 2007.

[2] D. Chu, C. Li, X. Xu, and X. Zhang, "A graph based framework for route optimization in sea-trade logistics," Mathematical Problems in Engineering, vol. 2015, Article ID 104326, 8 pages, 2015.

[3] Y.-C. Hu, Y.-J. Chiu, C.-S. Hsu, and Y.-Y. Chang, "Identifying key factors for introducing GPS-based fleet management systems to the logistics industry," Mathematical Problems in Engineering, vol. 2015, Article ID 413203, 14 pages, 2015.

[4] Z.-H. Liao, "The building research of innovative scientific and technological personnel competency model-based on the empirical investigation of 87 innovative talents of science and technology," Scientific and Technological Progress and Measures, vol. 9, p. 149, 2010.

[5] Z. Hu, Y. Zhang, and L. Yao, "Radial basis function neural network with particle swarm optimization algorithms for regional logistics demand prediction," Discrete Dynamics in Nature and Society, vol. 2014, Article ID 414058, 13 pages, 2014.

[6] L. Zhang, Y. Wang, T. Fei, and H. Ren, "The research on low carbon logistics routing optimization based on DNA-ant colony algorithm," Discrete Dynamics in Nature and Society, vol. 2014, Article ID 893851, 13 pages, 2014.

[7] J.-B. Fang, Strategic Performance Management, China People University Press, Beijing, China, 2007.

[8] T. L. Satty, Fundamentals of Decision Making and Priority Theory with the Analytic Hierarchy Process, RWS Publications, Princeton, NJ, USA, 1994.

[9] T. Yu, J. Zhou, K. Zhao, W. Wang, and W. Wang, "Study on project experts' evaluation based on analytic hierarchy process and fuzzy comprehensive evaluation," in Proceedings of the International Conference on Intelligent Computation Technology and Automation (ICICTA '08), pp. 941-945, IEEE, Hunan, China, October 2008.

[10] B. Li, G. Gu, B. Xing, and L. Li, "Ship electric propulsion simulation system reliability evaluation based on improved D-S expert weight calculation method," Mathematical Problems in Engineering, vol. 2015, Article ID 314058, 5 pages, 2015.

[11] K. Chang, Y. Chang, and H. Chung, "A novel AHP-based benefit evaluation model of military simulation training systems," Mathematical Problems in Engineering, vol. 2015, Article ID 956757, 14 pages, 2015.

[12] J.-T. Shi, Performance Management, Beijing Normal University Press, Beijing, China, 2007.

[13] T. L. Satty, The Analytic Hierarchy Process, McGraw-Hill, New York, NY, USA, 1980. 
[14] H. Sun and T. Ping, Network Analytic Hierarchy Process and Decision Science, National Defense Industry Press, Beijing, China, 2011.

[15] Y. Yuan and T. Yuan, "Design of individualized wheelchairs using AHP and Kano model," Advances in Mechanical Engineering, vol. 6, Article ID 242034, 2014.

[16] Y. Hou, D. Zhang, M. Luo, and B. Wu, "A cutting parameters selection method in milling aero-engine parts based on process condition matching," Advances in Mechanical Engineering, vol. 5, Article ID 157343, 2013.

[17] Y.-X. Feng, Y.-C. Gao, X. Song, and J.-R. Tan, "Equilibrium design based on design thinking solving: an integrated multicriteria decision-making methodology," Advances in Mechanical Engineering, vol. 5, Article ID 125291, 2013.

[18] D. Akbarian, "Ranking all DEA-efficient DMUs based on cross efficiency and analytic hierarchy process methods," Journal of Optimization, vol. 2015, Article ID 594727, 10 pages, 2015.

[19] M. Dabbagh and S. P. Lee, "An approach for integrating the prioritization of functional and nonfunctional requirements," The Scientific World Journal, vol. 2014, Article ID 737626, 13 pages, 2014.

[20] S.-B. Tsai, Y.-C. Lee, C.-H. Wu, and J.-J. Guo, "Examining how manufacturing corporations win orders," South African Journal of Industrial Engineering, vol. 24, no. 3, pp. 112-124, 2013.

[21] S. Tsai, R. Saito, Y. Lin, Q. Chen, and J. Zhou, "Discussing measurement criteria and competitive strategies of green suppliers from a green law perspective," Proceedings of the Institution of Mechanical Engineers : Journal of Engineering Manufacture, vol. 229, no. 1, supplement, pp. 135-145, 2015.

[22] S. Tsai, Y. Xue, P. Huang et al., "Establishing a criteria system for green production," Proceedings of the Institution of Mechanical Engineers, Part B: Journal of Engineering Manufacture, vol. 229, no. 8, pp. 1395-1406, 2015.

[23] J. L. Yang and G.-H. Tzeng, "An integrated MCDM technique combined with DEMATEL for a novel cluster-weighted with ANP method," Expert Systems with Applications, vol. 38, no. 3, pp. 1417-1424, 2011.

[24] L. Xu, D. T. Kumar, K. M. Shankar, D. Kannan, and G. Chen, "Analyzing criteria and sub-criteria for the corporate social responsibility-based supplier selection process using AHP," International Journal of Advanced Manufacturing Technology, vol. 68, no. 1-4, pp. 907-916, 2013.

[25] L. Xu, K. Mathiyazhagan, K. Govindan, A. N. Haq, N. V. Ramachandran, and A. Ashokkumar, "Multiple comparative studies of Green Supply Chain Management: pressures analysis," Resources, Conservation and Recycling, vol. 78, pp. 26-35, 2013.

[26] Y. Deng, Y. Liu, and D. Zhou, "An improved genetic algorithm with initial population strategy for symmetric TSP," Mathematical Problems in Engineering, vol. 2015, Article ID 212794, 6 pages, 2015.

[27] X. Zhang, Y. Zhang, Y. Hu, Y. Deng, and S. Mahadevan, "An adaptive amoeba algorithm for constrained shortest paths," Expert Systems with Applications, vol. 40, no. 18, pp. 7607-7616, 2013. 


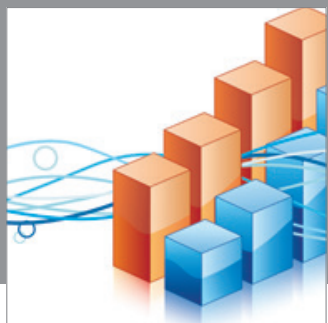

Advances in

Operations Research

mansans

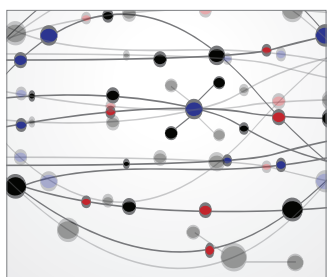

The Scientific World Journal
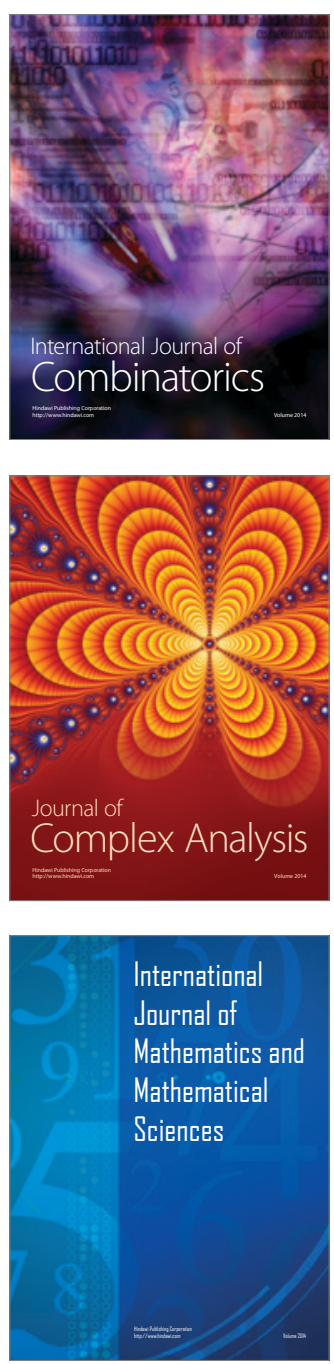
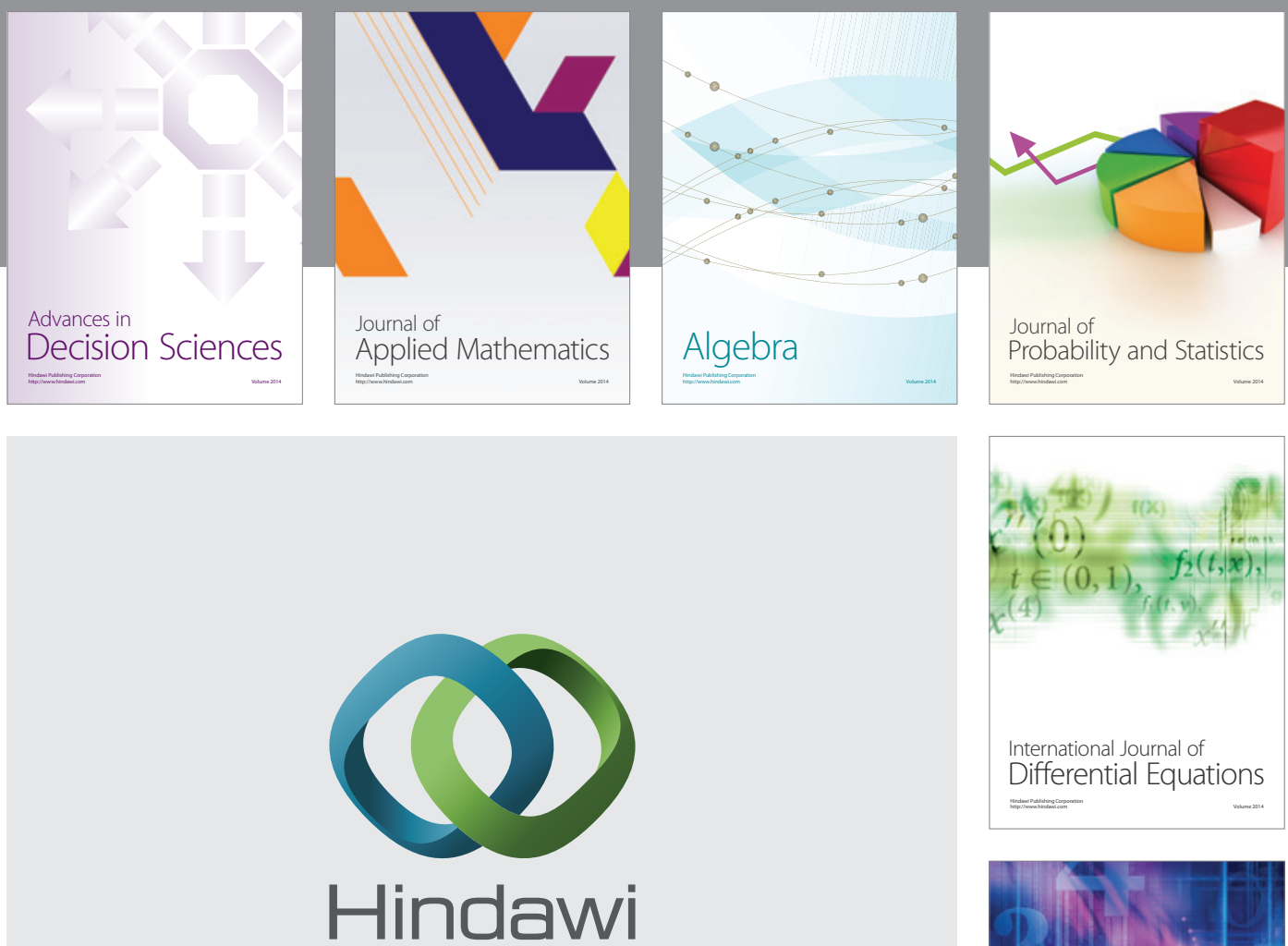

Submit your manuscripts at http://www.hindawi.com
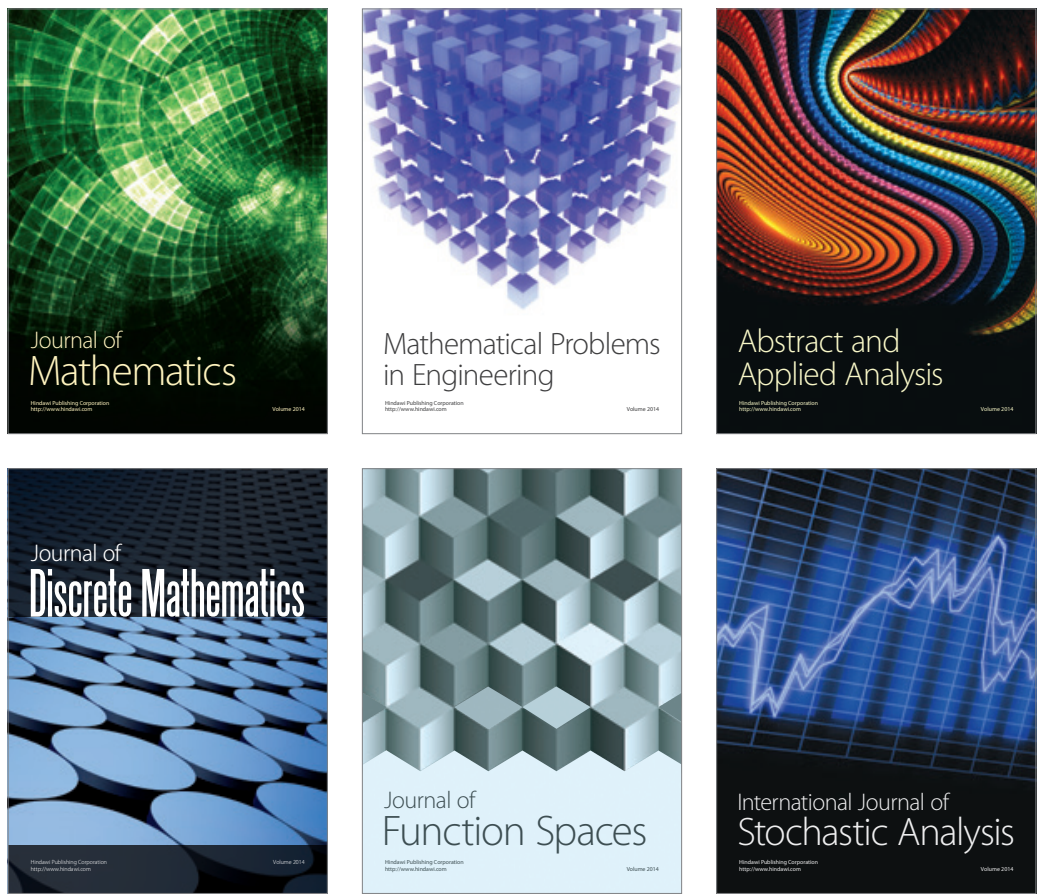

Journal of

Function Spaces

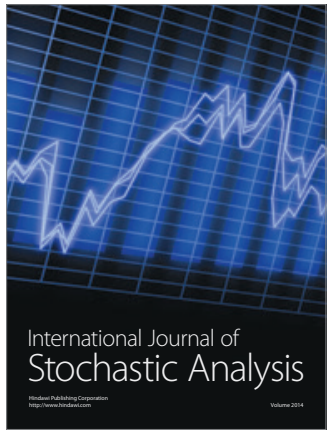

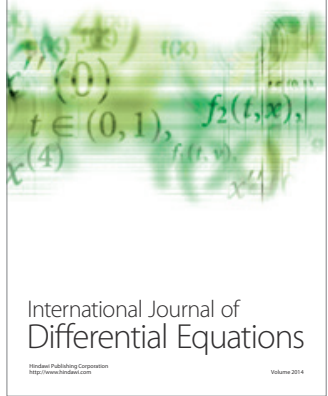
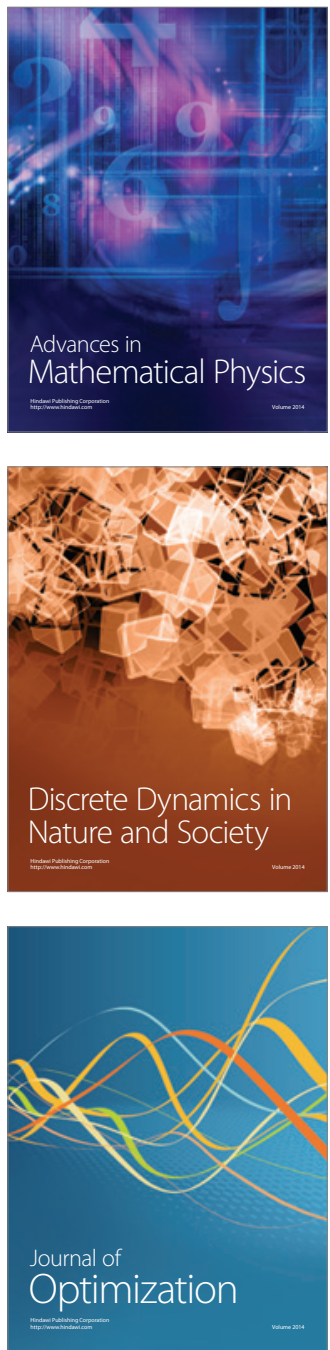